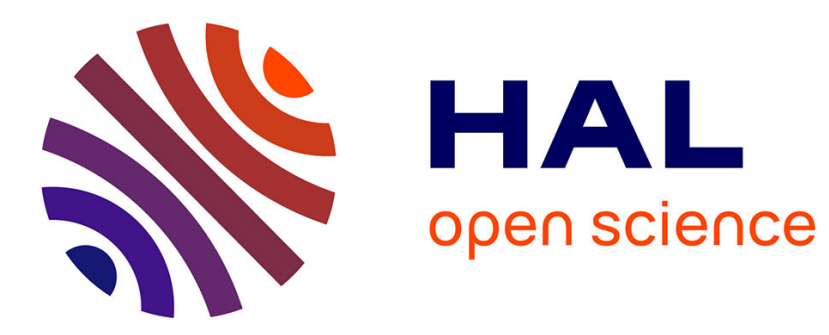

\title{
Contribution of a Knee Orthosis to Walking
}

Olivier Bordron, Yannick Aoustin, Clément Huneau, Eric Le Carpentier

\section{To cite this version:}

Olivier Bordron, Yannick Aoustin, Clément Huneau, Eric Le Carpentier. Contribution of a Knee Orthosis to Walking. Challenges and trends in Wearable Robotics, 2018, Pisa, Italy. hal-01985279

\section{HAL Id: hal-01985279 https://hal.science/hal-01985279}

Submitted on 17 Jan 2019

HAL is a multi-disciplinary open access archive for the deposit and dissemination of scientific research documents, whether they are published or not. The documents may come from teaching and research institutions in France or abroad, or from public or private research centers.
L'archive ouverte pluridisciplinaire HAL, est destinée au dépôt et à la diffusion de documents scientifiques de niveau recherche, publiés ou non, émanant des établissements d'enseignement et de recherche français ou étrangers, des laboratoires publics ou privés. 


\title{
Contribution of a Knee Orthosis to Walking
}

\author{
O. Bordron, C. Huneau, É. Le Carpentier, and Y. Aoustin
}

\begin{abstract}
This study is devoted to investigate the influence of a knee orthosis for human walking by using a mathematical model for a 7-links planar biped - composed with two identical legs, two feet and one trunk - with an orthosis attached to both thigh and calf, during walking. In the first part, we design a cyclic walking gait in the sagittal plane for human without the orthosis. The second part we consider that the human looses his muscular possibilities in one of his knees. To overcome his handicap the human is equipped of a knee orthosis. We analyse the positive effect of the orthosis over the assisted knee to track the previous designed reference trajectory. By using at each time an optimisation algorithm, we minimise the torques provided by the human. The numerical tests confirm the possibility to reduce the torque produced in the disabled knee. The next step is to take into account explicitly an information from EMG signal during a walking to modulate the power of the orthosis.
\end{abstract}

\section{INTRODUCTION}

Active orthosis have been developped in medical environment. They can be used for reducing chronic strains, compensating muscle impairments in case of rehabilitation or helping elderly people during walking (RobotKnee [1], EICoSI [2]).

Each assistive system has its own design, with its geometrical and mechanical properties. These features have an impact over walking and over the operator [3]. Then, to estimate the impacts of an orthosis over walking gait before designing the system is important.

Several studies using simulation and walking optimisation have already been done [4][5]. Nevertheless, walking gait optimisation has never been done for optimising the contribution of a knee orthosis. Depending on the reeducation stage of the patient, we propose to optimise the torque profile supplied by an orthosis. As we simply want to highlight the advantages and drawbacks of the proposed method, the study is carried out with a 2D planar model.

The biped model, walking gait and optimal trajectories are defined Section II. Then, the dynamic model is completed with an orthosis on the left knee. In Section III, the knee orthosis contribution is optimised to carry out the same walking.

\section{Material And Methods}

\section{A. Model of the biped}

The model used to simulate a step is illustrated Figure 1. This model is composed of one trunk, two legs - each one is composed with both a thigh and calf - and two feet. Model parameters of each link are those used in [8].

The left foot is considered flat on the ground (the left foot forms a complete joint with the ground), that is to say for any time $q_{\mathrm{p}_{1}}=0$ (see Figure 1), and the origin of the reference

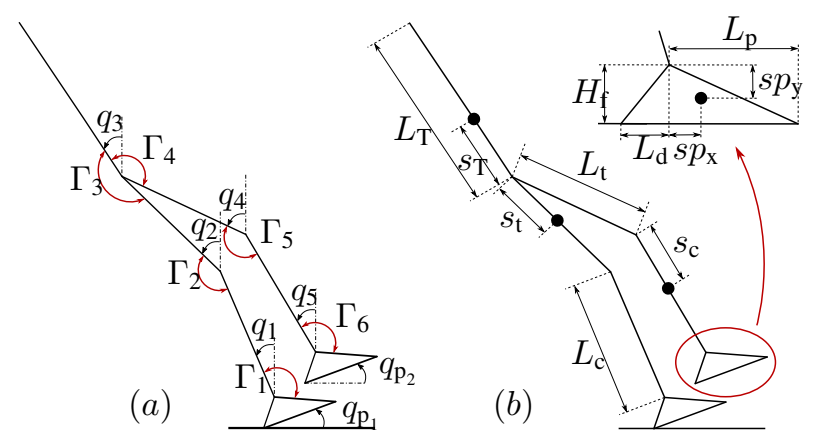

Fig. 1. Modelisation of the planed biped. a) Parameterisation of the biped. Note that angles are positive in counterclockwise. b) Length segments and position of the centers of mass.

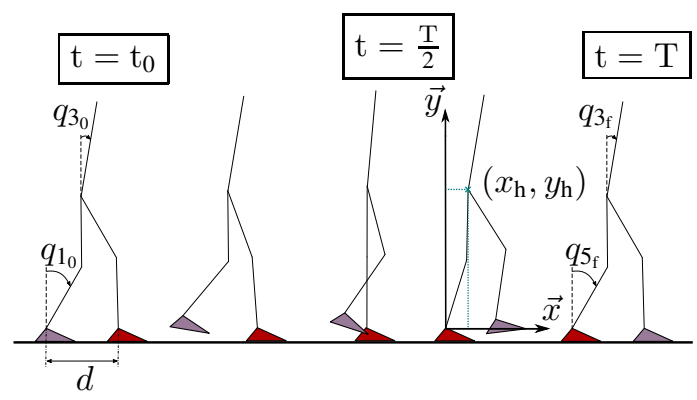

Fig. 2. A step of the biped and conditions of cyclicality.

frame is taken at the left ankle. The created dynamic model of the seven-link biped is detailed in [8].

\section{B. Definition of the optimal trajectories}

The walking gait studied here is cyclic. Thus the walking gait can be defined by designing over one step only (see Figure 2). This step is defined by a phase of single support and an impact with the ground. The impact model is the same used in [6]. We assume that trajectories describing the motion are defined by polynomial functions of fourth order, depending on time. By using cyclic conditions, we are able to describe the entire cyclic gait with these parameters:

$$
\left(x_{\mathrm{h}_{\mathrm{f}}}, y_{\mathrm{h}_{\mathrm{f}}}, d, q_{\mathrm{3}_{\mathrm{f}}}, \dot{\mathbf{q}}_{\mathrm{f}}, \mathbf{q}_{\text {int }}\right)
$$

$\left(x_{\mathrm{h}}, y_{\mathrm{h}}\right)$ is the configuration of the hip, $d$ the step length, $q_{3_{\mathrm{f}}}$ the final position of the trunk, $\dot{\mathbf{q}}_{\mathrm{f}}$ the final velocity and $\mathbf{q}_{\text {int }}$ the position at mid-cycle.

The design of the walking gait is made under the constraints: no take off and no sliding of the stance foot during the single support, the center of pressure must be inside the sole surface of the foot on the ground, and limits in magnitude of the joint torques and joint velocities.

The cost function used for optimisation is the normalised 


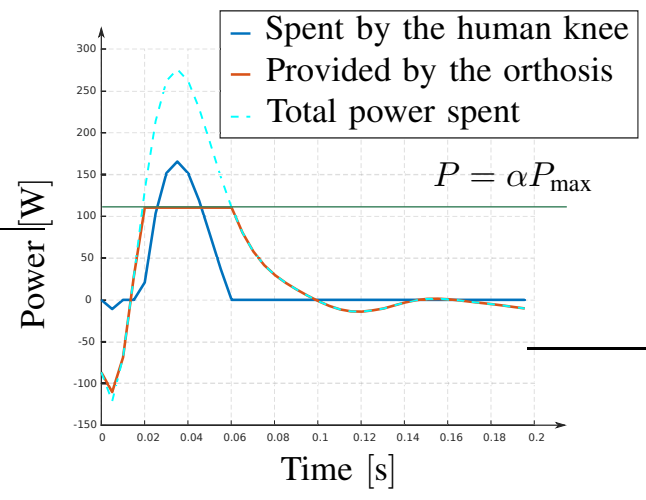

Fig. 3. Power of the knee at $v=1.0 \mathrm{~m} \cdot \mathrm{s}^{-1}$ and $\alpha=0.4$.

dynamic effort [7]. From a data set of (1), the Matlab ${ }^{\circledR}$ functions fmincon $^{\circledR}$ and MultiStart ${ }^{\circledR}$ are used to obtain the optimal trajectory in Figure 4.

\section{Contribution of the orthosis}

We add an orthosis to the biped model. It is modeled by one additional mass with inertia to both calf and thigh. Its features are those identified for the EICoSI orthosis [9]. Consequently, the dynamic model of the biped equipped with the orthosis changes [8].

In this study, we assume that the orthosis is positioned on the knee of the support leg. We are not interested here in the swing phase since the stance phase requires much more torque to the knee.

The torque profile supplied by the orthosis is optimised by using the same cost function as in II-B, under the constraint $P_{\text {orth }} \leq \alpha P_{\max } \cdot \alpha \in[0 ; 1]$ is a reeducation coefficient reflecting the assistive level needed for a patient. It varies throughout the reeducation. If $\alpha=0$, the knee is not assisted and if $\alpha=1$, the knee is fully assisted. $P_{\max }$ is the maximal power that must be provided by the knee to carry out the trajectory with the orthosis.

\section{RESULTS}

For example, at walking speed $v=1.0 \mathrm{~m} . \mathrm{s}^{-1}$, and for $\alpha=0.4$, the optimised torque profile of the orthosis is given Figure 3. The constraint $P_{\text {orth }} \leq \alpha P_{\max }$ is fulfilled. For $t \in$ $[0 ; 0.1]$, the patient has to provide power on the knee to carry out the trajectory defined in Section II. But for $t \in[0.1 ; 0.2]$, the orthosis provides all the power required to ensure the walking gait.

In the same way, we compute optimised torque profiles for different coefficient $\alpha$, at walking speed $v=1.0 \mathrm{~m} . \mathrm{s}^{-1}$. Energy distributions corresponding to these results are given Figure 5. They are normalised by the total energy spend at the knee to carry out the step. It shows that the assistive factor $\alpha$ introduced in Section II nearly corresponds to the normalised energy.

\section{CONCLUSION}

This paper has computed optimised torque profiles for the knee orthosis in order to carry out a given trajectory

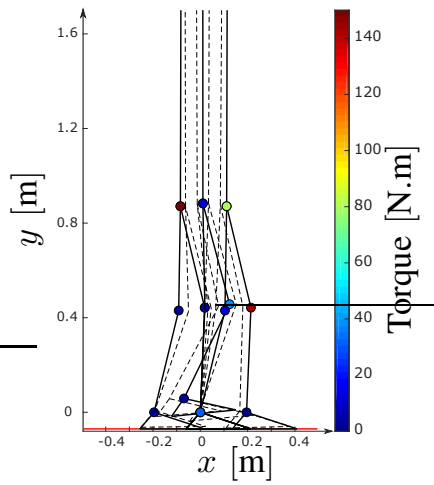

Fig. 4. An optimised step at walking speed $v=1.0 \mathrm{~m} \cdot \mathrm{s}^{-1}$.

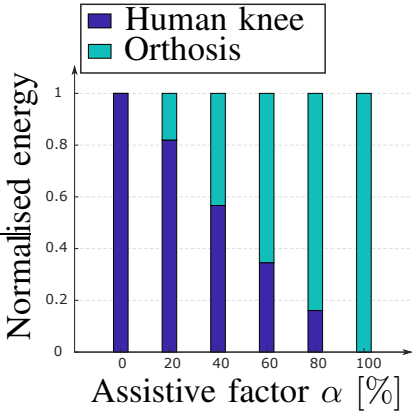

Fig. 5. Optimised contribution of the orthosis at $v=1.0 \mathrm{~m} . \mathrm{s}^{-1}$. (for instance the natural step of the patient), in the case of a simple planar model. The numerical tests confirm the possibility to reduce the torque produced in the disabled knee. Besides, we showed that the assistive level can be modulated by the introduction of the assistive factor $\alpha$.

Nevertheless, in the interests of realism, the model will be completed in a further step by taking into account the impedance of the joints. Indeed, the impedance of the tendonmuscle system can have a significant impact on the results. From this study, a possible extension is to extract information in time and amplitude from the power profile in order to efficiently control the orthosis. Another information could be extracted from the EMG signal to adjust the desired trajectory.

\section{REFERENCES}

[1] C. Schmitt, A study of a knee extension controlled by a closed loop functional electrical stimulation, Proc. 9th Annu. Conf. of the Int. FES Society, Bournemouth, 2004, pp. 135-137.

[2] S. Mefoued, A Second Order Sliding Mode Control and a Neural Network to Drive a Knee Joint Actuated Orthosis, Neurocomputing, vol. 155, May 2015, pp. 71-79.

[3] W. Huo, S. Mohammed, J. C. Moreno, and Y. Amirat, Lower Limb Wearable Robots for Assistance and Rehabilitation: A State of the Art, IEEE Systems Journal, vol. 10, Sept. 2016, pp. 1068-1081.

[4] D. Tlalolini, Y. Aoustin, and C. Chevallereau, Design of a walking cyclic gait with single support phases and impacts for the locomotor system of a thirteen-link 3D biped using the parametric optimization, Multibody System Dynamics, vol. 23, Sept. 2009, pp. 33.

[5] Y. Aoustin, A. M. Formalskii, Strategy to Lock the Knee of Exoskeleton Stance Leg: Study in the Framework of Ballistic Walking Model, in New Trends in Medical and Service Robots, vol. 3, Springer International Publishing, Ed. P. Wenger, C. Chevallereau, D. Doina, H. Bleuler, A. Rodi, 2016, pp. 179-195.

[6] Y. Aoustin, and A. M. Formalskii, Walking of Biped with Passive Exoskeleton: Evaluation of Energy Consumption, Multibody System Dynamics, Nov. 2017, pp. 1-26.

[7] Y. Xiang, J. S. Arora, and K. Abdel-Malek, Optimization-based prediction of asymmetric human gait, Journal of biomechanics, vol. 44(4), Feb. 2011, pp. 683-693.

[8] O. Bordron, É. Le Carpentier, C. Huneau, and Y. Aoustin, Impact of a Knee Orthosis over Walking, in ROMANSY 22 - Robot Design, Dynamics and Control, Springer International Publishing, Ed. V. Arakelian, P. Wenger, 2019, pp. 466-473.

[9] S. Mefoued, S. Mohammed, Y. Amirat, and G. Fried, Sit-to-Stand Movement Assistance Using an Actuated Knee Joint Orthosis, International Conference on Biomedical Robotics and Biomechatronics, Rome, 2012, pp. 1753-1758. 